TITLE:

Faulting process of the San Fernando earthquake of February 9, 1971 inferred from static and dynamic near-field displacements

$\operatorname{AUTHOR}(S)$ :

Mikumo, Takeshi

CITATION:

Mikumo, Takeshi. Faulting process of the San Fernando earthquake of February 9, 1971 inferred from static and dynamic near-field displacements. Bulletin of the Seismological Society of America 1973, 63(1): 249-269

ISSUE DATE:

1973-02

URL:

http://hdl.handle.net/2433/193384

RIGHT:

C) 1973, by the Seismological Society of America 


\section{FAULTING PROCESS OF THE SAN FERNANDO EARTHQUAKE OF FEBRUARY 9, 1971 INFERRED FROM STATIC AND DYNAMIC NEAR-FIELD DISPLACEMENTS}

By TAKESHI Mikumo

\section{ABSTRACT}

The faulting process of the San Fernando earthquake of February 9, 1971 has been investigated using the following seismic and geodetic data: vertical and horizontal displacements, strain and tilt changes, dynamic ground motions in the near-field, focal mechanism, spatial distribution of aftershocks and features of surface fault breaks. A synthetic study suggests that the earthquake was caused by thrust faulting with a slip of $233^{\circ}$ to $244^{\circ}$ over a fault plane with dimensions 19 by $14 \mathrm{~km}$, dip $50^{\circ}$ to $52^{\circ}$ and strike $N 64^{\circ}$ to $70^{\circ} \mathrm{W}$, which ruptures the ground surface over a distance of about $12 \mathrm{~km}$. The fracture initiating at the hypocenter of the main shock seems to have propagated radially over the fault plane with a velocity about $2.5 \mathrm{~km} / \mathrm{sec}$. A small dislocation less than $30 \mathrm{~cm}$ at initiation probably increased rapidly during propagation and reached 3.5 to $4 \mathrm{~m}$ at the ground surface.

A pronounced uplift and small subsidence of the ground north and south of the fault traces, and the overall pattern of the observed vertical and horizontal displacements can be explained well by the above model, but the recorded strain and tilt offsets are not always consistent with theoretical predictions. The wave forms and amplitudes for some of the integrated ground displacements from accelerograms at the Pacoima Dam and Pasadena are in fairly close agreement with those of the computed displacements. The seismic moment and stress drop of this earthquake were found to be $1.1 \times 10^{26} \mathrm{dyne} \cdot \mathrm{cm}$ and 40 to $65 \mathrm{bars}$, respectively.

\section{INTRODUCTION}

The San Fernando earthquake of February 9, 1971, with a magnitude of 6.6, occurred in the midst of a dense seismographic network in southern California. Extensive seismic observations, geodetic measurements, and engineering studies were made after the earthquake, and various results have been reported to date on: spatial distribution of aftershocks (Allen et al., 1971; Wesson et al., 1971; Hanks et al., 1971; Allen et al., 1972; Bolt and Gopalakrishnan, 1972), focal mechanism of the main shock and aftershocks (Whitcomb, 1971; Wesson et al., 1971; Dillinger and Espinosa, 1971; Canitez and Toksöz, 1972), geological features of surface faults (Kamb et al., 1971; U.S. Geological Survey Staff, 1971), pre- and post-earthquake tectonic movements (Burford et al., 1971; Savage et al., 1972), shearing strains before the earthquake (Whitten, 1971) static strain and tilt changes (Jungels and Anderson, 1971; Berger, 1971), and ground motions at various sites (Maley and Cloud, 1971; Hudson, 1971; Trifunac and Hudson, 1971; Trifunac, 1972; Bolt, 1972).

In this paper, we attempt to obtain a clear picture of the focal process of the main shock of the San Fernando earthquake, by synthesizing all available data. The orientation, shape, dimension and thrusting character of the fault plane are inferred from the spatial distribution of aftershocks and focal mechanism solutions, together with the location, length, and slip components of surface fault breaks. The amount of slip dis- 
location on the fault plane is estimated mainly from displacements of the surface faults, and tectonic movements, i.e., static, vertical, and horizontal displacements in the nearfield, with some reference to the strain and tilt offsets observed in the range between 100 and $350 \mathrm{~km}$. The direction and velocity of fracture propagation over the fault plane and the rise time of dislocation are derived from the dynamic ground displacements at the Pacoima Dam and Pasadena stations which have been obtained from accelerograms.

The fault models derived are compared with those inferred by other workers, and their tectonic implications are discussed.

\section{DATA}

Spatial distribution of aftershocks. The larger aftershocks (magnitudes greater than 3.0) that occurred within the 3 weeks from February 9 through March 1, 1971, are concentrated roughly in the shape of an inverted $U$, which has remarkable symmetry with

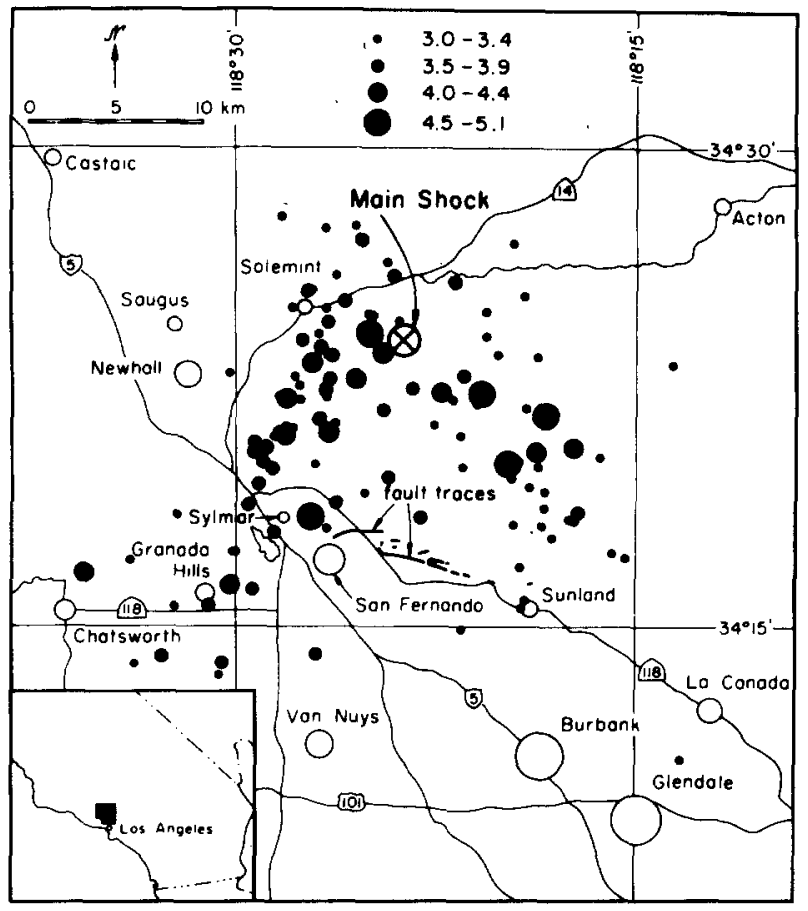

FIG. 1. Epicentral location of the main shock and aftershocks of magnitude 3.0 and greater of the San Fernando earthquake for the first 3 weeks of activity, February 9 through March 1, 1971 (Allen et al., 1971 ; reproduction permitted by Dr. C. R. Allen).

respect to the epicenter of the main shock and to the traces of surface faulting (Allen et al., 1971), as shown in Figure 1. Although these epicentral locations have been determined mainly from readings from permanent stations of the Caltech network with some supplementary information, temporary observations of smaller shocks from portable seismograph network within short-time sampled intervals also indicate similar epicentral distribution (Wesson et al., 1971; Hanks et al., 1971). It is interesting that the larger aftershocks along the periphery of the epicentral area seem to delineate the boundary of slippage of the thrust fault. There is, however, the relative absence of aftershocks in the area just north of the surficial fault traces (Allen et al., 1971; Wesson et al., 1971), presumably because stresses were completely relieved there (Allen et al., 1972). 
The focal depths of these aftershocks generally increase toward the north from 5 to $7 \mathrm{~km}$ below the zone of ground breakage to 12 to $15 \mathrm{~km}$ at the northern limit of activity (Wesson et al., 1971; Allen et al., 1972), defining relatively well a slab-shaped zone dipping about $30^{\circ}$ to $40^{\circ}$. The preliminary hypocenter of the main shock at a depth of $13 \mathrm{~km}$ (Allen et al., 1971) seems to fall on the lower boundary of the aftershock zone (Wesson et al., 1971).

Focal mechanism solutions. The focal mechanism of the main shock has been determined, with the double-couple assumption, from $P$-wave first motions recorded at nearby stations of the Caltech and the U.S. Geological Survey, and at the WWSSN stations in teleseismic distances, together with supplementary information from some other organizations (Whitcomb, 1971; Wesson et al., 1971; Dillinger and Espinosa, 1971; Canitez and Toksöz, 1972). The parameters specifying the two nodal planes of the four solutions are given in Table 1. A nodal plane dipping northeast is well-defined in all of

TABLE 1

Parameters of the Nodal Planes

\begin{tabular}{|c|c|c|c|c|c|}
\hline \multirow{2}{*}{ Solutions } & \multicolumn{2}{|c|}{ Plane I } & \multicolumn{2}{|c|}{ Plane II } & \multirow{2}{*}{ Reference } \\
\hline & Strike & Dip & Strike & Dip & \\
\hline 1 & $\mathrm{~N} 64^{\circ} \mathrm{W}$ & $52^{\circ}$ & $\mathrm{N} 26^{\circ} \mathrm{W}$ & $44^{\circ}$ & Whitcomb (1971) \\
\hline 2 & $\mathrm{~N} 72^{\circ} \mathrm{W}$ & $50^{\circ}$ & $\mathrm{N} 34^{\circ} \mathrm{W}$ & $46^{\circ}$ & Wesson et al. (1971) \\
\hline 3 & $\mathrm{~N} 60^{\circ} \mathrm{W}$ & $50^{\circ}$ & $\mathrm{N} 60^{\circ} \mathrm{W}$ & $40^{\circ}$ & Dillinger and Espinosa (1971) \\
\hline 4 & $\mathrm{~N} 70^{\circ} \mathrm{W}$ & $52^{\circ}$ & $\mathrm{N} 37^{\circ} \mathrm{W}$ & $43^{\circ}$ & Canitez and Toksöz (1972) \\
\hline
\end{tabular}

the four solutions, which gives similar estimates for its dip and strike, whereas the determination of the secondary plane is rather uncertain probably because of poor coverage of stations in the southwest quadrant. The apparent dip of the first plane along the NS direction is about $47^{\circ}$ to $49^{\circ}$, which is nearly parallel to the slope of the aftershock zone as well as to the line connecting the hypocenter of the main shock and the position of surface breaks.

Surface faulting. Extensive surveys of fault breaks that occurred during the earthquake, by the Caltech (Kamb et al., 1971) and the U.S. Geological Survey groups (1971), revealed that the zone of surface faulting, which consists mainly of the Sylmar and Tujunga segments, extends almost continuously with overall trend of $\mathrm{N} 72^{\circ} \mathrm{W}$ over a distance of at least $12 \mathrm{~km}$, with small intermittent indications (Kamb et al., 1971). The average displacement along the zone is the vertical uplift of $1 \mathrm{~m}$, north-south compression of $0.9 \mathrm{~m}$ and left-lateral slip of $1 \mathrm{~m}$ (U.S. Geological Survey Staff, 1971), although local maximum displacements reach twice the average. The overall features of fault movement near the surface can be represented by thrusting of a northern block southwestward over a southern block along a fault plane dipping about $42^{\circ}$ toward $\mathrm{N} 20^{\circ} \mathrm{E}$ (Kamb et al., 1971).

Other observed data including tectonic movements, strain and tilt changes and strong ground motions will be described in later sections, comparing them with theoretical calculations.

\section{Assumed FAult Model}

The above evidence indicates a high degree of consistency among the inclination of aftershock distribution, the dip of surface faults and the apparent dip of the first nodal plane derived from the focal mechanism solution, and also between the strike of the 
plane and the observed trend of surface faults. It is reasonable, therefore, to consider this plane as the fault plane, and the small differences in the dips might be attributed to local flexure of the plane. A reasonable hypothesis is that the initial rupture took place at the hypocenter and then thrust faulting propagated southward and upward over the fault plane reaching the ground surface in the Sylmar-Tujunga area (Allen et al., 1971).

It has been pointed out (Whitcomb, 1971; Allen et al., 1972), however, that this interpretation encounters some difficulty in explaining: first, the strike-slip mechanism of somewhat deeper aftershocks in the southwest region, and second, the occurrence of aftershocks south of the projected trace of the thrust plane, i.e., near Granada Hills and Chatworth. Allen et al., (1972) presented an idea that these problems may be accounted for by introducing a north-trending flexure of the fault plane that steeply steps down by 3 to $5 \mathrm{~km}$ west of the zone. However, all of the aftershocks west of the presumed flexure took place in a later period of activity (Allen et al., 1972). For this reason, we take here a simple interpretation that the fault surface of the main shock may be modeled by a flat and nearly rectangular plane, at least to a first approximation.
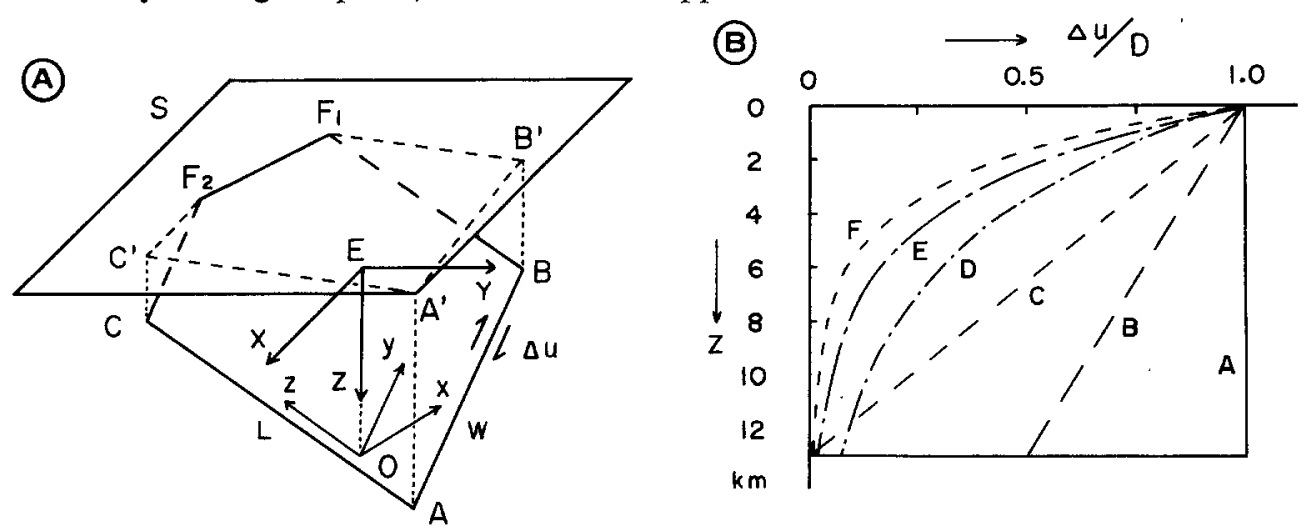

FIG. 2. (A) Schematic representation of the fault model adopted and the coordinate systems. (B) Distribution of the assumed dislocations against depth ( $D$ is the dislocation at the ground surface).

The slip direction of thrust faulting over the plane can be estimated from the focal mechanism solutions. Whitcomb's solution (1971) shows a plunge of $44^{\circ}$ and a rake of $244^{\circ}$, whereas Canitez and Toksöz (1972) gave the corresponding rake of $225^{\circ}$ (from surface waves) and $233^{\circ}$ ( from $P$ waves). We refer mainly to the former solution in later discussion, but with some reference to the latter solution, because the strike of the fault plane in the latter is closer to the trend of surface fault traces.

The dimension of the dipping fault plane may be taken as 10 to $14 \mathrm{~km}$ along the slip vector, and 15 to $19 \mathrm{~km}$ parallel to the null vector, from the horizontal extent of the epicentral area bounded by larger aftershocks. In later computations, the fault dimension is varied in the above range, but we adopted the largest area (14 by $19 \mathrm{~km})$ in the final model. Because this dipping plane with the dimension intersects obliquely the ground surface over some length, trending $\mathrm{N} 64^{\circ}$ to $70^{\circ} \mathrm{W}$, we regard here the trace of intersection as the southern boundary of the fault plane.

The focal depth of the main shock has been preliminarily located at about $13 \mathrm{~km}$ (Allen et al., 1971), but later revised to $8.4 \mathrm{~km}$ (Allen et al., 1972), on the basis of traveltime correction factors and the use of a larger number of close-in stations. The revised depth has, however, an uncertainty up to 4 to $8 \mathrm{~km}$, and also introduces slightly larger inconsistencies into the various evidence described before. The spectra of surface waves also supports a focal depth around $14 \mathrm{~km}$ (Canitez and Toksöz, 1972). For these reasons, we take, in this study, the preliminary depth of $13 \mathrm{~km}$ rather than the revised value. 
Figure 2A schematically illustrates the fault model assumed here. The fault plane $A B F_{1} F_{2} C$ intersects the ground surface $S$ over the fault trace $F_{1} F_{2}$, and $A^{\prime} B^{\prime} F_{1} F_{2} C^{\prime}$ indicates the aftershock area. $E$ and $O$ are taken at the epicenter $\left(34^{\circ} 24.0^{\prime} \mathrm{N}: 118^{\circ} 23.7^{\prime} \mathrm{W}\right)$ and at the hypocenter $(13 \mathrm{~km})$ which lies on the fault plane. For later computations, the coordinate axes $O x, O y$ and $O z$ are taken normal to the fault plane, parallel to the slip vector, and parallel to the null vector, respectively, and the $y z$-plane is chosen to coincide with the fault plane. $E X, E Y$ and $E Z$ are taken eastward, northward and downward, respectively. The two coordinate systems are related by,

$$
\left(\begin{array}{l}
x \\
y \\
z
\end{array}\right)=\left(\begin{array}{lll}
l_{1} & m_{1} & n_{1} \\
l_{2} & m_{2} & n_{2} \\
l_{3} & m_{3} & n_{3}
\end{array}\right)\left(\begin{array}{c}
X \\
Y \\
Z
\end{array}\right)
$$

$l_{j}, m_{j}$ and $n_{j}$, the direction cosines of the $x_{j}$ axes ( $i=1,2$ and 3 correspond to $x, y$ and $z$, - respectively) with respect to the $X_{j}$ axes $(j=1,2$ and 3 correspond to $X, Y$ and $Z$, respectively) are,

$$
l_{j}=\cos \psi_{j} \cdot \sin \beta_{j}, \quad m_{j}=\cos \psi_{j} \cdot \cos \beta_{j} \text { and } n_{j}=-\sin \psi_{j}
$$

where $\psi_{j}$ and $\beta_{j}$ are the plunge and trend of the $x_{j}$ axes, respectively.

Figure $2 \mathrm{~B}$ gives the assumed distributions of slip dislocations with depth, which will be later estimated mainly from the observed tectonic movements during the earthquake.

\section{STATIC DisPlaCEMENTS}

Tectonic movements. Comparison between pre- and post-earthquake geodetic measurements of leveling, triangulation, trilateration etc. disclosed large-scale tectonic movements including elevation and length changes in the northern part of the San Fernando Valley along the front of the San Gabriel Mountains (Burford et al., 1971; Savage et al., 1972). The most striking features of the movements are the pronounced uplift combined with strong northward tilt on the north side of the fault traces, and small subsidence on the footwall to the south, as seen from the contour map (Figure 3) compiled by Savage et al., (1972). The uplift just north of the fault breaks reaches 1 to $2.5 \mathrm{~m}$, and abruptly decreases to about $0.5 \mathrm{~m}$ within 2 to $4 \mathrm{~km}$ toward the north and to $1 \mathrm{~m}$ within $1 \mathrm{~km}$ at the south edge of the north block, although there is significant warping of the pattern as well as differences in uplift between the Sylmar and Tujunga segments. The pattern of the horizontal movements compiled by Savage et al., (1972) is reproduced in Figure 4, indicating rather complex features. Some lines which cross the eastern zone of surface rupture tend to be shortened, whereas the others seem to be lengthened. The largest displacement with a westward motion of $2 \mathrm{~m}$ comes from PL1 (Burford et al., 1971), although this might be due partly to surficial down-slope movement (Savage et al., 1972).

Most of the pre-earthquake data are based on the surveys completed in the period 1930 to 1940 , but strain accumulation after 1935 (Whitten, 1971) does not seem to be large enough to give significant errors in the post-earthquake measurements (Savage et al., 1972).

Theoretical displacements. In this section, we calculate theoretical, static displacements based on the fault models described before, in order to explain the tectonic movements that occurred during the San Fernando earthquake.

The theoretical formulation for static displacements resulting from dislocation models in a half-space has been derived for various cases (Steketee, 1958; Chinnery, 1963; Maruyama, 1964; Press, 1965; Mansinha and Smylie, 1971). These theories have been successfully applied to simple fault models for some large shallow earthquakes (Savage 


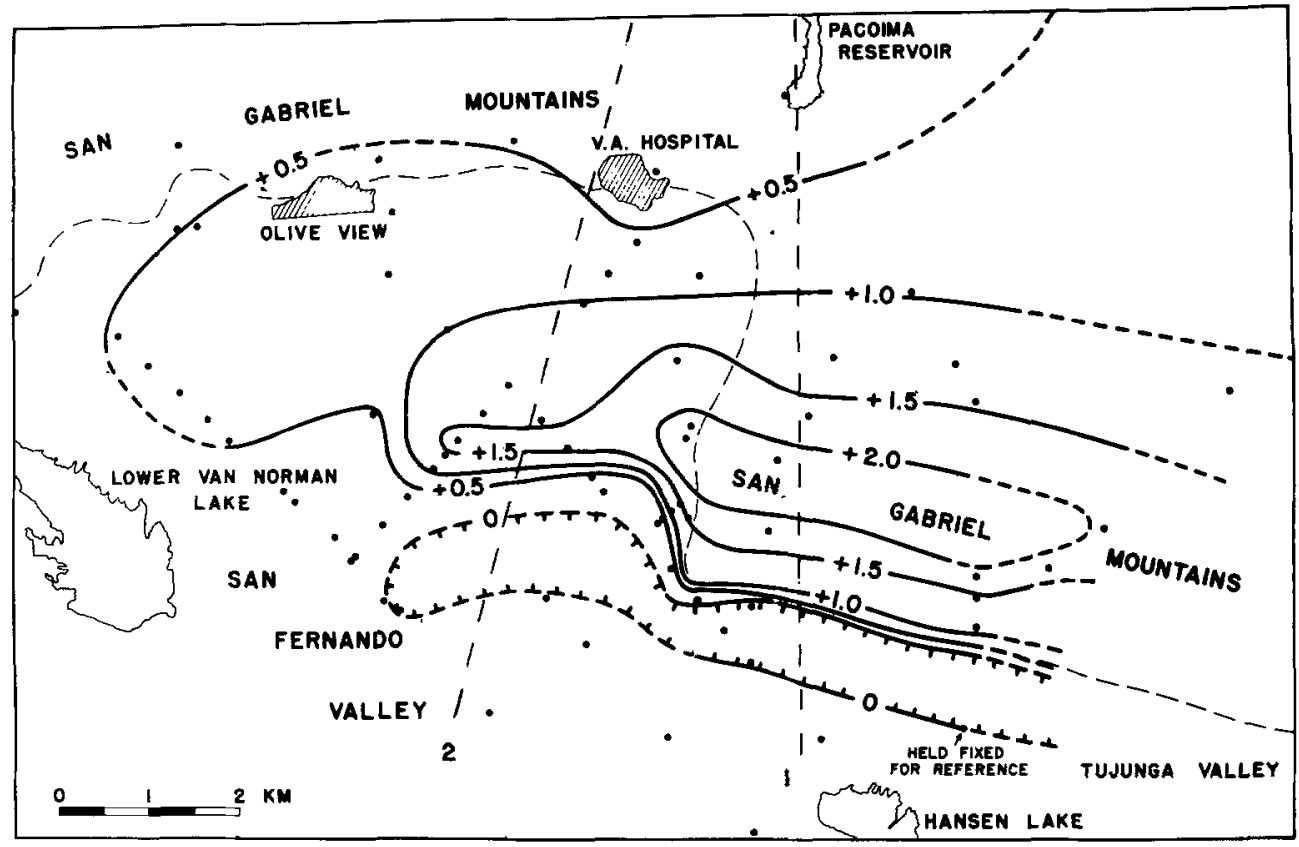

CONTOUR MAP OF RELATIVE ELEVATION CHANGES IN METERS

FIG. 3. Vertical displacements (relative elevation changes in meters) for part of the area surrounding the surface ruptures (Savage et al., 1972; reproduction permitted by Dr. J. C. Savage).
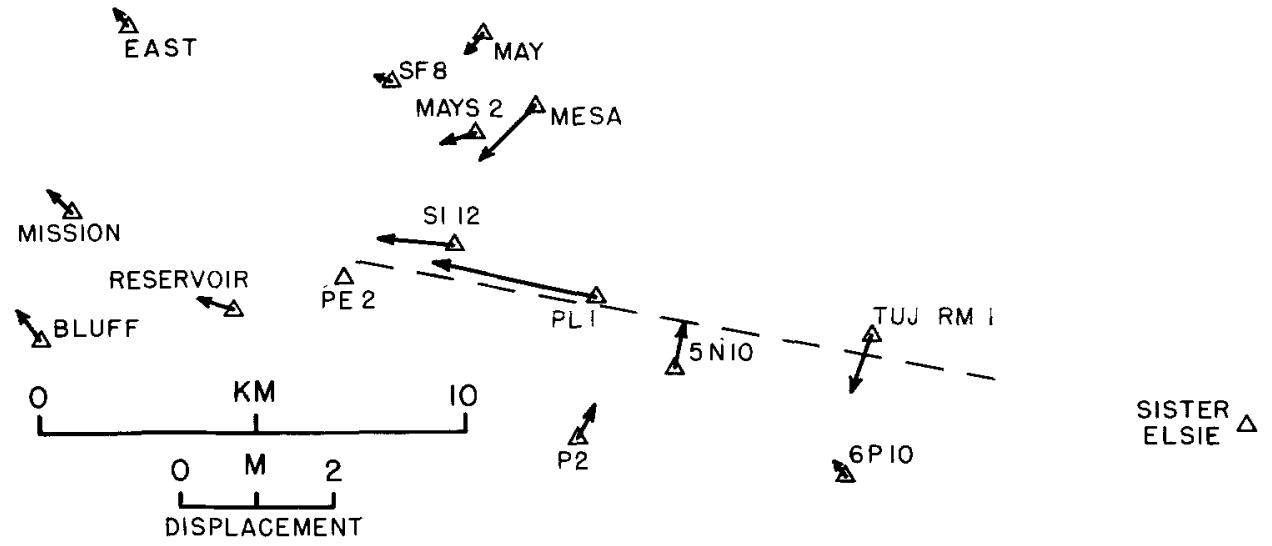

FIG. 4. Horizontal displacements (relative length changes) in the area (Savage et al., 1972; reproduction permitted by Dr. J. C. Savage).

and Hastie, 1966, 1969; Plafker and Savage, 1970; Hastie and Savage, 1970; Ando, 1971; Fitch and Scholz, 1971; Savage, et al., 1972; Canitez and Toksöz, 1972). In most of the cases, however, the fault plane was assumed to be rectangular, and the slip dislocation was constant over the plane. In the present case, the fault plane with a rather complicated form is dipping in such a way that the directions of its length and width intersect obliquely the surface fault trace (see Figure $2 \mathrm{~A}$ ), and also it seems quite likely that the amount of dislocation varies with depth, because pre-earthquake stresses and frictional stress during faulting may not be uniformly distributed with depth (Chinnery and Petrak, 1968). In this paper, therefore, we refer to the most general formulation derived by Maruyama (1964). 
The static displacement $u_{m}$ at a point on the ground surface caused by a slip dislocation zan be expressed as (Maruyama, 1964),

$$
u_{m}=\iint \Delta u_{k} \cdot w_{k l}^{m} v_{l} d \Sigma
$$

where $\Delta u_{k}(k=1,2,3)$ are the dislocation components, $v_{l}$ are the direction cosines of the normal to the slip plane, $d \Sigma$ is the surface element, and $w_{k l}^{m}$ are the displacement tensors, the form of which are given in Maruyama's paper (1964). We shall calculate $u_{m}$ referring to the $X Y Z$ coordinate system (Figure 2A), by choosing $k, l$ and $m$ to coincide with each one of the $X_{j}$ axes $(j=1,2,3)$. Since a slip dislocation $\Delta u$ is assumed to occur along the $y$-axis which was taken parallel to the slip vector, the dislocation components $\Delta u_{k}$ along the directions of the $X_{k}$ axes $(k=1,2,3)$ are, $\Delta u_{1}=l_{2} \Delta u, \Delta u_{2}=$ $m_{2} \Delta u$ and $\Delta u_{3}=n_{2} \Delta u$. The direction cosines of the normal are, $v_{1}=l_{1}, v_{2}=m_{1}$ and $v_{3}=n_{1}$. Equation (2) then reduces to

$$
\begin{aligned}
u_{m}= & \iint\left[l_{2}\left(l_{1} w_{11}^{m}+m_{1} w_{12}^{m}+n_{1} w_{13}^{m}\right)\right. \\
& +m_{2}\left(l_{1} w_{21}^{m}+m_{1} w_{22}^{m}+n_{1} w_{23}^{m}\right) \\
& \left.+n_{2}\left(l_{1} w_{31}^{m}+m_{1} w_{32}^{m}+n_{1} w_{33}^{m}\right)\right] \Delta u d \Sigma .
\end{aligned}
$$

In this case, $x_{1}, x_{2}$ and $\xi_{3}$ involved in the tensors $w_{k l}^{m}$ in Maruyama's expression are replaced by $X_{1}-\left(l_{2} \xi+l_{3} \eta\right), X_{2}-\left(m_{2} \xi+m_{3} \eta\right)$, and $H+\left(n_{2} \xi+n_{3} \eta\right)$, respectively, where $\xi, \eta$, and $H$ are the location of a surface element and the depth of the origin, respectively.

The above integrations were evaluated numerically over the fault plane as $\iint d \Sigma=$ $\int_{0}^{\mathrm{w}} d \xi \int_{0}^{\mathrm{L}} d \eta$ by dividing the entire area into $1.0 \times 1.0 \mathrm{~km}$ elements. Contributions from the portion above the ground surface were excluded (see Figure 2A). The accuracy of the numerical computations was checked in the case of a vertical strike-slip fault by comparison with the analytical solution by Press (1965). The difference was found to be less than 0.2 per cent. In the above computation, we assumed different distributions of dislocation as shown in Figure 2B, where $D$ is the surface dislocation.

The vertical and horizontal displacements computed for a fault model with constant dislocation $D$ are shown by contour lines and arrows, respectively, in Figures 5, A and B. Two broken oblique lines are the projection of two nodal planes from Whitcomb's (1971) focal mechanism solution, and a small area bounded by dotted lines shows the horizontal projection of the fault plane. It is found that the general pattern of both displacements indicates a good agreement with that of the observed tectonic movements as shown in Figures 3 and 4.

However, a close comparison reveals some discrepancies. Figures 6, A and B, gives the observed (solid circles) and computed vertical displacements along the two profiles through the epicenter as indicated in Figure 3 . The computed curves $A, B, C, D, E$ and $F$ correspond to the different distributions of dislocations with depth assumed in Figure $2 \mathrm{~B}$. We also assumed various values of the surface dislocation $D$, but, in these figures, $D$ is tentatively taken to be $4 \mathrm{~m}$. It is immediately clear that the observed displacements decay more rapidly toward the north than the case $A$; in other words, the constant dislocation model does not explain the observed tectonic features. In the cases $B$ and $C$, dislocations are assumed to decrease linearly with depth, whereas they decay exponentially in the cases $D, E$ and $F$. The observations along profile 1 may be well explained by $D$ or $E$, if we take about $4 \mathrm{~m}$ for the surface dislocation, although the computed downward displacements are larger than the measured subsidence. An alternative assumption (case $G$ ) is that dislocations decrease with depth in a form of $D \cdot \exp \left(-\alpha Z^{2}\right)$ as in the case discussed by Chinnery and Petrak (1968). It is found that $D \cong 4.5 \mathrm{~m}$ and $\alpha=0.06 \mathrm{~m}^{-2}$ give the best fit to the observations. 


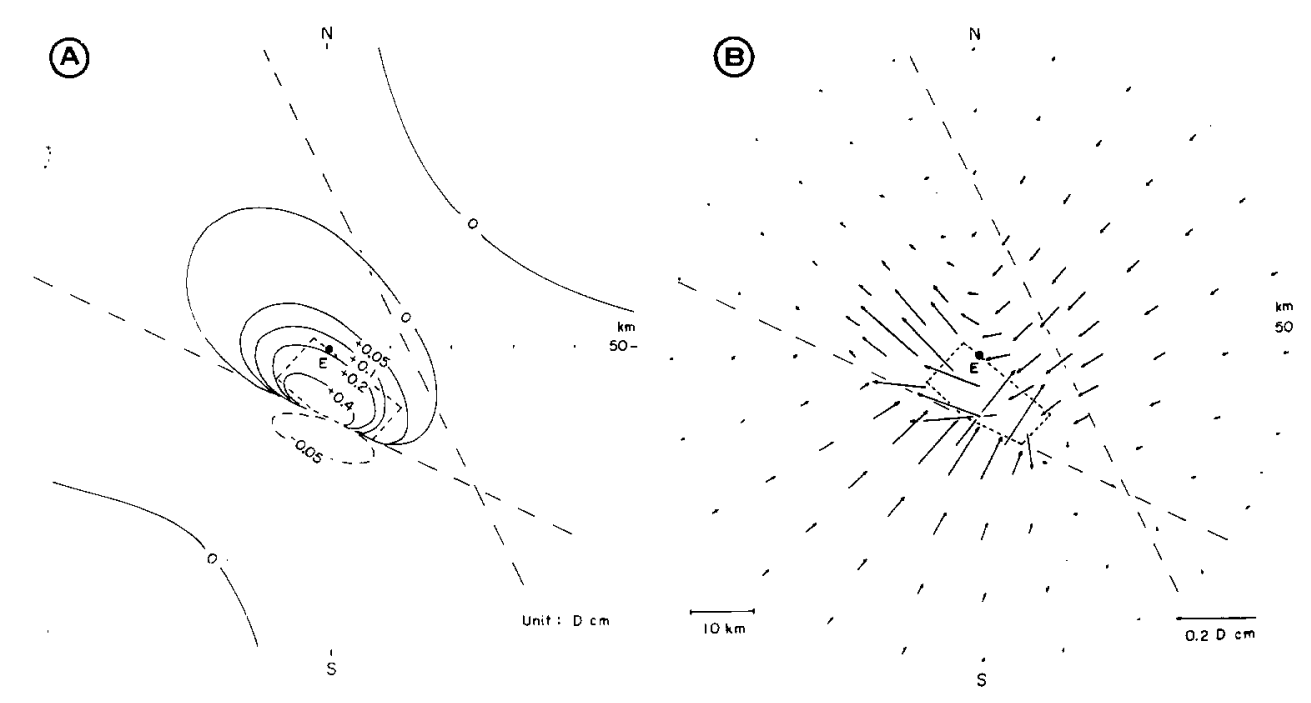

FIG. 5. (A) Computed vertical displacements from a fault model with constant dislocation.

(B) Computed horizontal displacements from a fault model with constant dislocation.

The situations are somewhat different for profile 2. Since this profile goes nearly across the edge $F_{1}$ (Figure 1A), the peak displacement around there tends to be singular. For this reason, we tentatively assume that the dislocations over the fault plane gradually decrease toward the both sides $B F_{1}$ and $A C$, similar to Chinnery and Petrak (1968), in such a way that

$$
\Delta u \propto 1-|1-2 \xi / W|^{n}
$$

$(n=10)$. This assumption yields larger surface displacements in the eastern part of the fault trace $F_{1} F_{2}$ than in the west, and, hence, seems consistent with some differences in the surveyed fault displacements between the Tujunga and Sylmar segments. The computation under this assumption yields peak values of 190 to $200 \mathrm{~cm}$ for the cases $D$ and $E$, which seems somewhat larger than the measured displacement along this profile. If the surface dislocation is taken to be $3.5 \mathrm{~m}$ instead of $4 \mathrm{~m}$, the peak displacements would fall to about $150 \mathrm{~cm}$, and, hence, agreement with the observations would be improved.

If we refer to Canitez-Toksöz' focal mechanism solution instead of to Whitcomb's, the strike of the fault trace $F_{1} F_{2}$ would rotate more east-westerly by $6^{\circ}$. Figure $6 \mathrm{C}$ gives similar displacements along profile 1 , with the same assumption as above, for the cases $D$ and $E$. Again, the computed peak values are larger than the corresponding observations, and a reduction from $4 \mathrm{~m}$ to $3.5 \mathrm{~m}$ in the surface dislocation would reconcile this discrepancy.

Geological survey of the surface fault (Kamb et al., 1971) suggests that local maximum displacement might reach about $2 \mathrm{~m}$, in each of the vertical, left-lateral and north-south compression components, which would give a net displacement of about $3.5 \mathrm{~m}$. The amount of 3.5 to $4 \mathrm{~m}$ derived from the foregoing considerations seems consistent with this inference, although this is considerably larger than that of 2.0 to $2.4 \mathrm{~m}$ estimated from the average of the three components (Kamb et al., 1971; U.S. Geological Survey Staff, 1971). The difference might be attributed to near-surface conditions including complex geology, which could reduce the average displacement. 


\section{(A)} cm

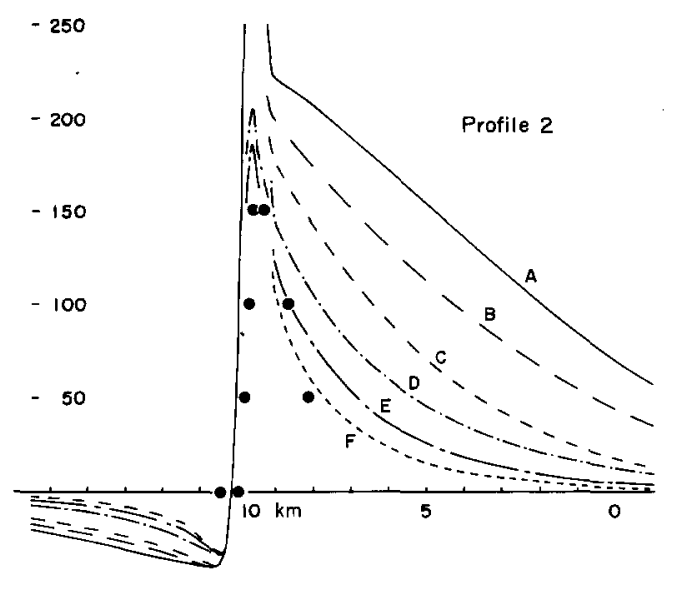

(B)

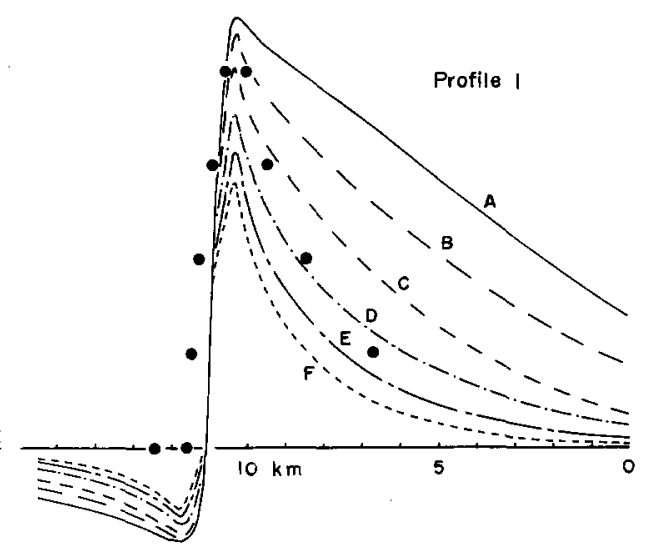

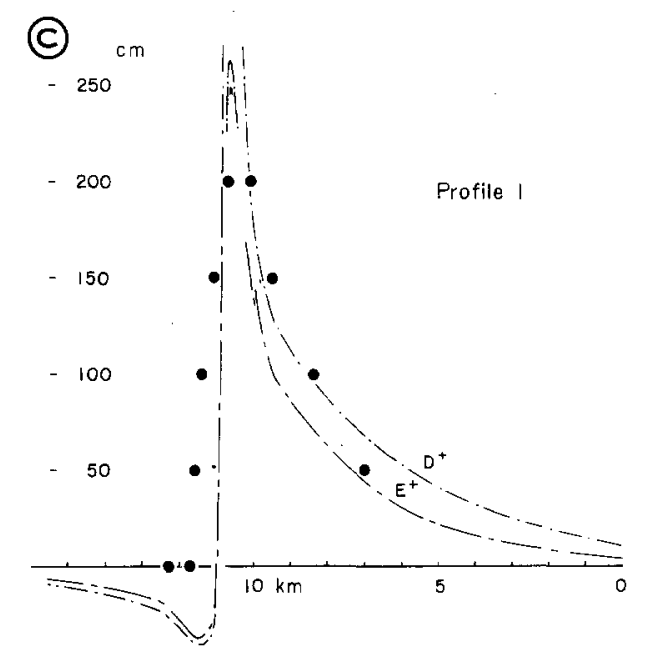

FIG. 6. Observed and computed vertical displacements along two profiles. Data (solid circles) were taken from Savage et al., (1972), and the computed curves are from the dislocation models given in Figure 2(B). (A) Profile 2. (B) Profile 1, based on Whitcomb's focal mechanism solution (1971) (C) Profile 1, based on Canitez-Toksöz' focal mechanism solution (1972).

The pattern of the computed vertical displacements from model D is shown in Figure 7. This seems to explain more reasonably the observed movements shown in Figure 3. The horizontal displacements from the same model are given in Figure 8. We see that the observed horizontal displacements (Figure 4) can be well explained by this model except for PLI and MESA. The discrepancy may be due to surficial movements, as suggested by Savage et al. (1972).

\section{Strain Changes}

Strain offsets. During the San Fernando earthquake, permanent strain offsets have been recorded at the following four sites; by two components of strain seismographs at Isabella, $147 \mathrm{~km}$ north of the epicenter, on three strain meters at the Nevada Test Site, $380 \mathrm{~km} \mathrm{NE}$ (Jungels and Anderson, 1971), on an interferometric laser strain meter at the University of California, San Diego, $210 \mathrm{~km} \mathrm{SE} \mathrm{(Berger,} \mathrm{1971),} \mathrm{and} \mathrm{by} \mathrm{three} \mathrm{strain} \mathrm{meters}$ 
at Stone Canyon, $360 \mathrm{~km} \mathrm{NW} \mathrm{(Pfluke,} \mathrm{personal} \mathrm{communication,} \mathrm{1972).} \mathrm{Besides} \mathrm{these,}$ tilt steps were also observed on the Isabella mercury tiltmeters (Jungels and Anderson, 1971). The observed offsets are tabulated in Table 2. Similar strain steps have been observed at several stations in Japan at the time of a few large shallow Japanese earthquakes, particularly during the Gifu earthquake of September $9,1969(M=6.6)$ (The Japanese Network of Crustal Movement Observatories, 1970). These observations might be due partly to local strain release or to instrumental effects of ground shaking, but some of them probably result from real changes in the strain field caused by generation of faulting.

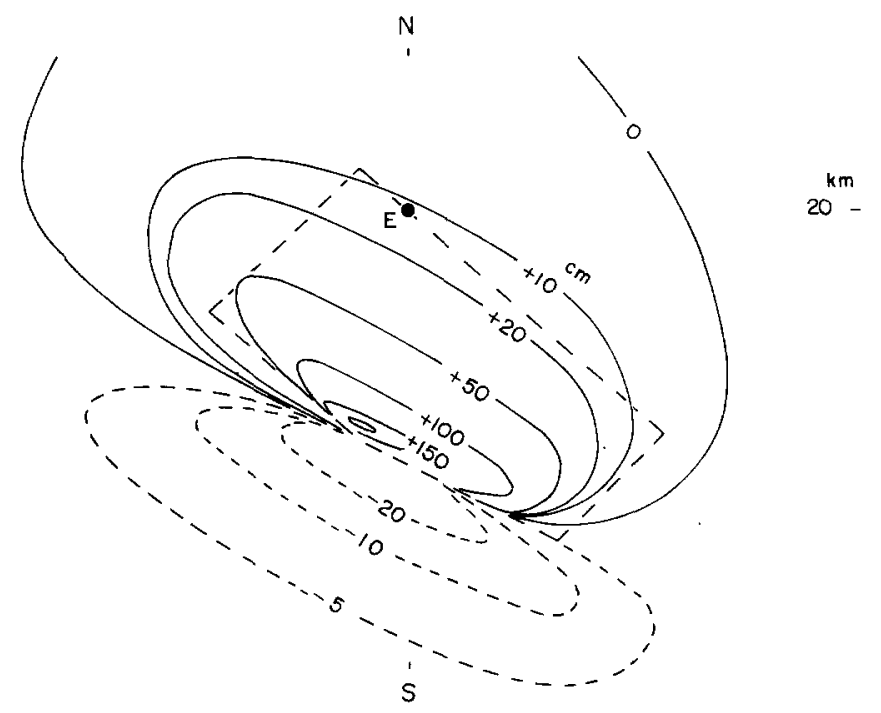

FIG. 7. Computed vertical displacements from the final model D.

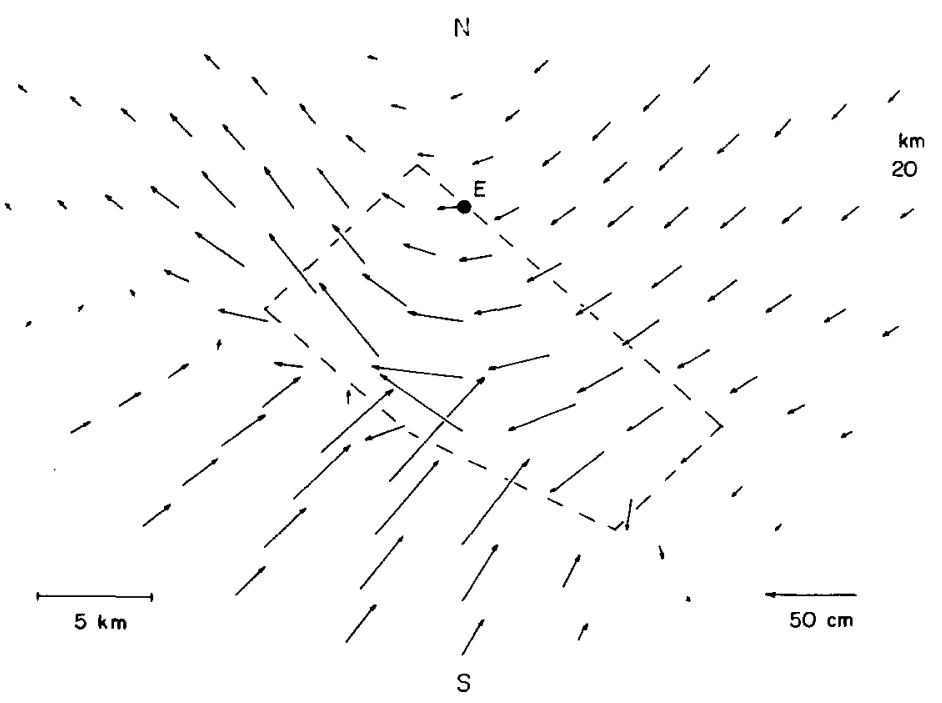

FIG. 8. Computed horizontal displacements from the final model D. 
TABLE 2

Observed and Computed Strain and Tilt Changes*

\begin{tabular}{|c|c|c|c|c|c|c|c|c|c|c|c|}
\hline \multirow{4}{*}{ 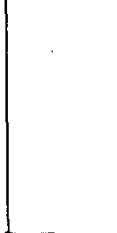 } & \multicolumn{2}{|c|}{ Station } & \multicolumn{2}{|c|}{$\begin{array}{c}\text { ISA } \\
\text { Strain }\end{array}$} & $\begin{array}{c}\text { UCSD } \\
\text { Strain }\end{array}$ & \multicolumn{2}{|c|}{$\begin{array}{l}\text { NTS } \\
\text { Strain }\end{array}$} & \multicolumn{2}{|c|}{$\begin{array}{c}\text { STC } \\
\text { Strain }\end{array}$} & \multirow{2}{*}{\multicolumn{2}{|c|}{$\begin{array}{c}\text { ISA } \\
\text { Tilt } \\
\text { N51:7 N } 38^{\circ} .3 \mathrm{~W}\end{array}$}} \\
\hline & & N51:7E & $1138^{\circ} 3$ & $N 45^{\circ} \mathrm{E}$ & N45i: & N75ㅍ & NS & N135E & & \\
\hline & & & $10^{-9}$ & $10^{-8}$ & $10^{-9}$ & $10^{-10}$ & $10^{-9}$ & $10^{-10}$ & $10^{-10}$ & $10^{-9}$ & $10^{-9}$ \\
\hline & \multicolumn{2}{|c|}{ Observed } & 4.19 & 1.36 & -1.6 & 3. & 0.3 & 40. & 60. & $<7$. & -100 \\
\hline Model & & Coeff. & & & & & & & & & \\
\hline A & & $\begin{array}{lll}\text { L } & 0.0\end{array}$ & -16.11 & 3.14 & -8.51 & -19.56 & 4.57 & -12.12 & -12.53 & 18.52 & 8.64 \\
\hline B & 4.0 & $L-0.5$ & -11.68 & 2.23 & -6.40 & -14.05 & 3.27 & -8.98 & -9.15 & 13.15 & 5.74 \\
\hline$c$ & 1.0 & $\mathrm{~L}-1.0$ & -6.95 & 1.52 & -4.29 & $-9.5 ?$ & 2.23 & -5.87 & -5.73 & 9.25 & 4.75 \\
\hline D & 4.0 & E -0.2 & -4.97 & 1.10 & -3.10 & -6.84 & 1.61 & -4.25 & -4.14 & 0.66 & 3.45 \\
\hline $\mathrm{E}$ & 4.0 & $\mathrm{i}:-0.3$ & -3.21 & 0.74 & -2.11 & -4.60 & 1.08 & -2.86 & -2.72 & 4.53 & 2.43 \\
\hline F & 4.0 & $\because-0.4$ & -2.25 & 0.53 & -1.54 & -3.30 & 0.78 & -2.16 & -1.92 & 3.78 & 1.80 \\
\hline$c^{\prime}$ & 3.0 & $\mathrm{~L}-1.0$ & -5.15 & 1.14 & -3.06 & -7.13 & 1.67 & -4.40 & -4.29 & 6.94 & 3.56 \\
\hline$D^{\prime}$ & 3.5 & $1 .-0.2$ & -4.35 & 0.96 & -2.71 & -5.97 & 1.40 & -3.72 & -3.62 & 5.82 & 3.02 \\
\hline$E^{\prime}$ & 4.5 & E -0.3 & -3.62 & 0.83 & -2.38 & -5.17 & 1.22 & -3.22 & -3.06 & 5.10 & 2.73 \\
\hline $\mathrm{D}^{+}$ & 4.0 & E -0.2 & -3.33 & 1.50 & -3.63 & -7.09 & 1.66 & -4.67 & -2.58 & 5.36 & 4.71 \\
\hline $\mathrm{D}^{+1}$ & 3.5 & $E-0.2$ & -2.91 & 1.31 & -3.17 & -6.20 & 1.45 & -4.08 & -2.26 & 4.69 & 4.03 \\
\hline D* & 4.0 & E -0.2 & -2.53 & 1.72 & -4.13 & -7.49 & 1.70 & -4.45 & -0.64 & 4.63 & 4.97 \\
\hline$D^{* \prime}$ & 3.5 & $E-0.2$ & -2.21 & 1.50 & -3.61 & -6.55 & 1.48 & -3.89 & -0.56 & 4.05 & 4.35 \\
\hline
\end{tabular}

* Minus sign in the strains indicates compression. $L$ means a linear decrease and $E$ means an exponential decrease of dislocations with depth, and Coeff. indicates its coefficient. Observed data for ISA and NTS are from Jungels and Anderson (1971), for UCSD from Berger (1971), and for STC from Pfluke (personal communication, 1972).

Computed strains and tilts. We compute, here, theoretical strains and tilts from the foregoing fault models, to compare with the observations. The strain components $\partial u_{1} / \partial X_{1}, \partial u_{1} / \partial X_{2}, \partial u_{2} / \partial X_{1}$ and $\partial u_{2} / \partial X_{2}$ and the tilt components $\partial u_{3} / \partial X_{1}$ and $\partial u_{3} / \partial X_{2}$ can be directly derived by differentiating equation (2) or (3) with respect to $X_{j}(j=1,2)$,

$$
\frac{\partial u_{m}}{\partial X_{j}}=\iint \Delta u_{k} \frac{\partial w_{k l}^{m}}{\partial X_{j}} v_{l} d \Sigma .
$$

It is easy to calculate $\partial w_{k l}^{m} / \partial X_{j}$ from the displacement tensors $w_{k l}^{m}$, but because their derivations are rather lengthy, they are omitted here. The strain components along any two perpendicular directions $X^{\prime}$ and $Y^{\prime}$ are,

$$
\begin{aligned}
& e_{X X}^{\prime}=\left(\partial u_{1} / \partial X_{1}\right) \cos ^{2} \varphi+\left(\partial u_{2} / \partial X_{2}\right) \sin ^{2} \varphi-\left(\partial u_{2} / \partial X_{1}+\partial u_{1} / \partial X_{2}\right) \sin \varphi \cdot \cos \varphi \\
& e_{Y Y}^{\prime}=\left(\partial u_{1} / \partial X_{1}\right) \sin ^{2} \varphi+\left(\partial u_{2} / \partial X_{2}\right) \cos ^{2} \varphi+\left(\partial u_{2} / \partial X_{1}+\partial u_{1} / \partial X_{2}\right) \sin \varphi \cdot \cos \varphi \\
& e^{\prime}{ }_{X Y}=\left(\partial u_{1} / \partial X_{1}-\partial u_{2} / \partial X_{2}\right) \sin 2 \varphi+\left(\partial u_{1} / \partial X_{2}+d u_{2} / \partial X_{1}\right) \cos 2 \varphi
\end{aligned}
$$

where $\varphi$ is the azimuth measured clockwise from the $X_{2}(Y)$ axis. The principal strains and the corresponding azimuth are obtained from the extrema of $e_{X X}^{\prime}$ or $e_{Y Y}^{\prime}$. The tilt components along the two directions are

$$
\begin{aligned}
& i_{X}^{\prime}=\left(\partial u_{3} / \partial X_{1}\right) \cos \varphi-\left(\partial u_{3} / \partial X_{2}\right) \sin \varphi \\
& {i^{\prime}}_{Y}=\left(\partial u_{3} / \partial X_{1}\right) \sin \varphi+\left(\partial u_{3} / \partial X_{2}\right) \cos \varphi
\end{aligned}
$$

and the maximum tilt and the corresponding azimuth are determined from equation (6). 
Figure 9, A and B, shows the principal strain (extension and contraction) and maximum tilt fields within $50 \mathrm{~km}$ from the epicenter, respectively, based on the fault model with constant dislocations. The patterns are rather complicated because of complex configuration and finite dimension of the fault plane. The corresponding strain and tilt fields from model D extending to $250 \mathrm{~km}$ are given in Figure 10 , A and $\mathrm{B}$, together with the location of the four stations mentioned above. It is seen that the patterns in this range tend to become rather regular as compared with those for the shorter distances.

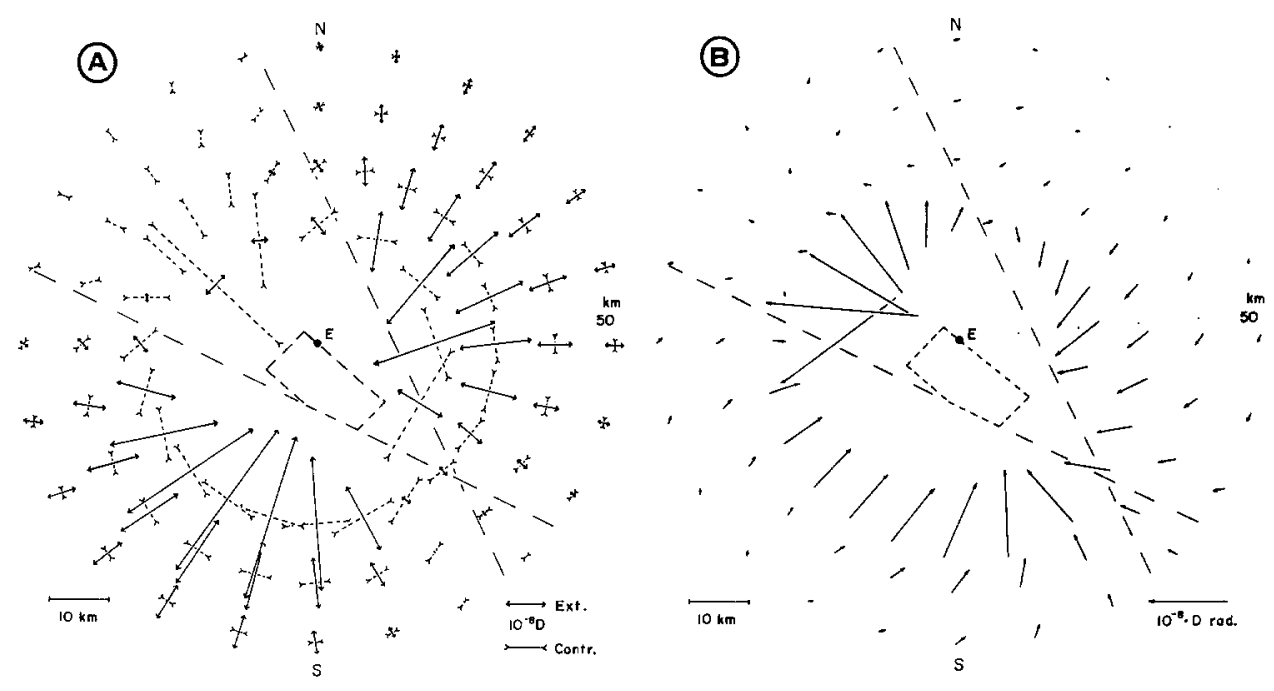

FIG. 9. (A) Computed principal strains within $50 \mathrm{~km}$ from a fault model with constant dislocation. (B) Computed maximum tilts within $50 \mathrm{~km}$ from a fault model with constant dislocation.

OSTC

N

NTSO

N

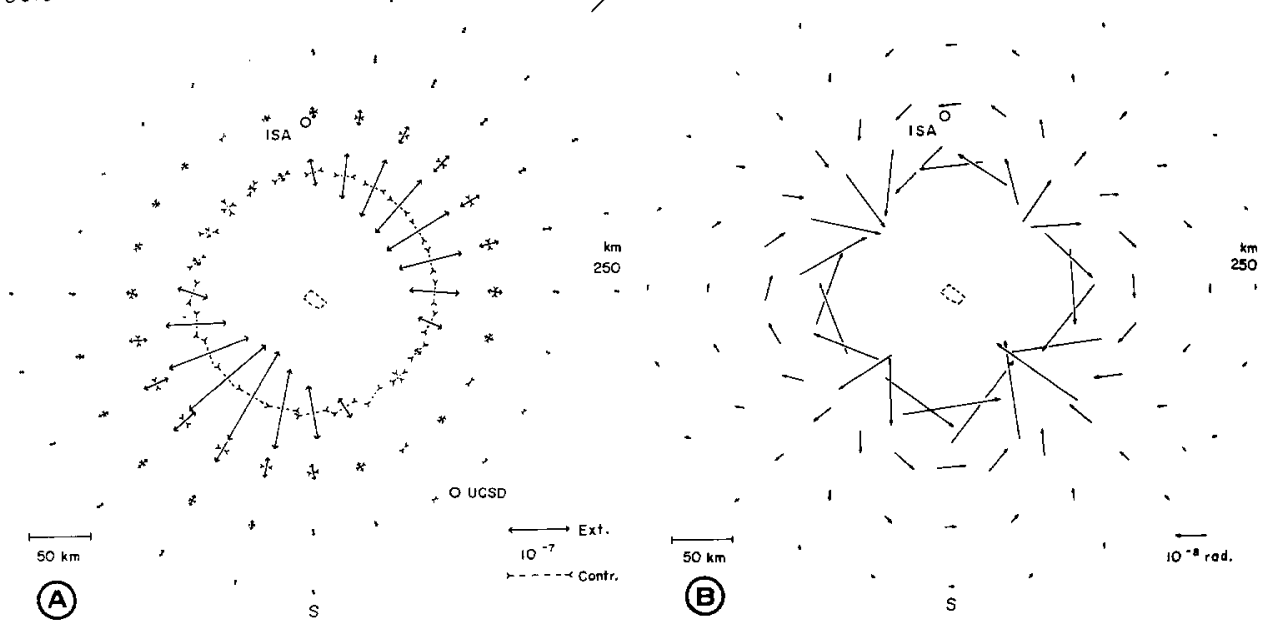

FIG. 10. (A) Computed principal strains within $250 \mathrm{~km}$ from the final model D. (B) Computed maximum tilts within $250 \mathrm{~km}$ from the final model D. 
The strains and tilts along the specific directions of instruments at the stations are computed for the different models assumed before, and the results are summarized in Table 2. Comparison of these values with the corresponding observations indicates that models D, E and G give the right order of magnitude for the ISA strains and one component of tilts, for the UCSD strain, and for one component of the NTS strains, although the observed strains for the ISA N $51.7^{\circ} \mathrm{E}$ and the NTS N45 $\mathrm{W}$ components exhibit reverse signs. The reverse sense for Isabella might be due to the fact that this station lies near a nodal curve of strains as seen from Figure 10A. However, computations from these models do not yield good agreement with the observations for the NTS N75 ${ }^{\circ} \mathrm{E}$ strain, the STC strains, and the ISA N38. $3^{\circ} \mathrm{W}$ tilt. A better fit could be obtained for each of the components if the area of the fault plane and/or the amount of dislocation are somewhat adjusted, but these alterations encounter greater difficulties to account for the other observations as well as for the observed tectonic movements. Comparison of the strain steps from the Gifu earthquake with the corresponding theoretical changes from some reasonable fault models also indicates similar discrepancies and reverse signs, particularly at remote stations (Mikumo, in preparation). The recorded offsets are sometimes larger by one or two orders of magnitude than the expected values. Because strains and tilts could be significantly affected by local geological structure and topographic environments around recording stations, the theoretical half-space model used here may not be a good approximation. Also, some disturbances resulting from instrumental effects could disturb recording of the small strains down to $10^{-10}$.

For this reason, we do not reach a definite conclusion as to whether all of the observed strain and tilt changes are direct consequences of faulting. It can only be said that models $\mathrm{D}, \mathrm{E}$ and $\mathrm{G}$ predict the parameters somewhat better than the others considered.

\section{DYNAMIC DisPLACEMENTS}

Ground motions. Strong ground motion was recorded at the time of the San Fernando earthquake on over 200 accelerographs at various sites mostly in and near the Los Angeles area (Maley and Cloud, 1971). From a seismological point of view, it is interesting that some of the accelerographs set up on the ground fully recorded ground motion in the very near-field from the earthquake within distances comparable with the fault dimension. Of particular interest is the Pacoima Dam site, which was located at about $7 \mathrm{~km}$ south of the epicenter, $4 \mathrm{~km}$ north of the surface fault breaks and right above the presumed fault plane. It is reasonable to suppose that the ground motion here was strongly subjected to the effects of the faulting process, as well as to the surface structure. Trifunac and Hudson (1971) gave integrated ground velocities and displacements from the accelerograms recorded at the Pacoima Dam. Similar integrated records have been computed for four Pasadena stations and some other sites (Hudson, 1972). It is expected that these records provide a useful clue to the velocity and direction of fracture propagation over the fault plane.

Computed displacements. We attempt to calculate theoretical, dynamic displacements appropriate to the Pacoima Dam and one of the Pasadena stations (Seismological Laboratory) in comparison with the integrated ground motions, to estimate the dynamic fault parameters. The other parameters specifying the fault dimension and dislocation, etc., are based on the static models described in the previous section. In order to compute the dynamic near-field displacements, we refer to the formulations given by Maruyama (1963) and Haskell (1969), which are appropriate to moving dislocations in an infinite, homogeneous medium. These expressions are only approximate for the present fault model, and, therefore, the results presented here should be regarded as only preliminary. 
More complete calculations will be made in the near future. However, Aki (1968) and Kanamori $(1971$; 1972) have successfully explained the seismograms recorded in the near-field from some large earthquakes, on the basis of the above infinite-medium theories.

Following Maruyama (1963), the displacement $u_{m}(t)$ caused by slip dislocation $\Delta u_{k}(t)$ at an arbitrary point in an infinite medium can be written as

$$
\begin{aligned}
& u_{m}(t)=\iint T_{k l}^{m}\left[\psi_{k}\right] v_{l} d \Sigma \\
& \psi_{k}(t)=\int_{0}^{t} d t^{\prime} \int_{0}^{t^{\prime}} \Delta u_{k}\left(t^{\prime \prime}\right) d t^{\prime \prime}
\end{aligned}
$$

where the component. $T_{k l}^{m}\left[\psi_{k}\right]$ is given in Maruyama's paper, and $t-r / a$ and $t-r / b$ in his expression are replaced by $t-\zeta / v-r / a$ and $t-\zeta / v-r / b$ for moving dislocation, $v$ being the fracture velocity. We shall calculate first $u_{m}(t)$ referring to the $x y z$ coordinate system, in which,

$$
\begin{gathered}
r_{x}=\alpha_{1} r_{0}, r_{y}=\alpha_{2} r_{0}-\xi, r_{z}=\alpha_{3} r_{0}-\eta, \\
r=\left[r_{0}^{2}+\xi^{2}+\eta^{2}-2 r_{0}\left(\alpha_{2} \xi+\alpha_{3} \eta\right)\right]^{1 / 2},
\end{gathered}
$$

and

$$
\alpha_{j}=l_{j} \sin \Theta \sin \Phi+m_{j} \sin \Theta \cdot \cos \Phi+n_{j} \cos \Theta, \quad(j=1,2,3)
$$

for a surface element $(\xi, \eta)$ on the fault plane, where $\Theta$ and $\Phi$ are the zenith angle and azimuth measured at the origin, respectively. The displacements referring to the $X Y Z$ coordinate system, or their components along the observational directions can be directly obtained from $u_{x}, u_{y}$ and $u_{z}$ using the direction cosines $l_{j}, m_{j}$ and $n_{j}$, or the instrumental orientations.

The time dependence of dislocation is assumed to be a ramp function as given by Haskell (1969), where the rise time $\tau$ is taken from $0.2 \mathrm{sec}$ (similar to a step function up to $4 \mathrm{sec}$ ). We assume three different modes of fracture propagation with a constant velocity; (a) radial propagation from the hypocenter $O,\left[\zeta=\left(\xi^{2}+\eta^{2}\right)^{1 / 2}\right]$, (b) unilateral propagation along the direction $W\left(A C \rightarrow B F_{1}\right)[\zeta=\xi$, $(0<\xi<W]$, (c) bilateral propagation from $O$ along the direction $L(\zeta=|\eta|(0<|\eta|<L)$. The fracture velocity $v$ is assumed to take three different values, $2.0,2.5$ and $3.0 \mathrm{~km} / \mathrm{sec}$. The $P$-wave velocity in the epicentral region is taken to be $6.10 \mathrm{~km} / \mathrm{sec}$ from a recent seismic refraction measurement (Wesson and Gibbs, 1971), and the $S$-wave velocity is assumed as $3.50 \mathrm{~km} / \mathrm{sec}$.

To evaluate equation (7), numerical integrations are performed on 0.5 by $0.5 \mathrm{~km}$ elements over the fault area. The length of the divided elements seems reasonable in view of Aki's test (1968). To compensate the effects of the free surface, we tried to apply two different methods. The first was that the displacements resulting from each elementary dislocation are resolved into $P, S V$, and $S H$ components along each ray path and then multiplied by the reflection coefficient at the surface appropriate to these components. After doing this, the compensated displacements were again corrected for the $X Y Z$-coordinate system, and all contributions from the entire fault surface were superposed. This approach includes a plane-wave assumption and, hence, is still approximate. Trial computations with these compensations were not successful in comparison with the integrated ground displacements, probably because the computed displacements involve a permanent step. The alternative approach taken here was to simply double the computed displacements, as suggested by Haskell (1969) and practically applied by Aki (1968) and Kanamori (1971; 1972). This correction seems appropriate for waves mainly of $S H$ motion, but, otherwise, not necessarily justifiable. 
The integrated ground displacements given by Trifunac and Hudson (1971) do not include period components longer than $16 \mathrm{sec}$. To compare with these displacements, we apply a boxcar-type band-pass filter with cutoff periods at 20 and $0.4 \mathrm{sec}$ to the computed displacements by a convolution technique, rejecting both permanent displacements and short-period noise. Slight deviation from the zero line at the onset of the filtered records and their amplitudes have been corrected by comparing with the results obtained simply by taking off a linear trend from the computed displacements.

Figure 11A gives the vertical displacements computed for the Pacoima $\operatorname{Dam}(X=$ $0.0 \mathrm{~km}, Y=-7.0 \mathrm{~km}$ ) from radial propagation of fracture with a rise time of $1 \mathrm{sec}$ for three different velocities, in comparison with the corresponding ground displacement.
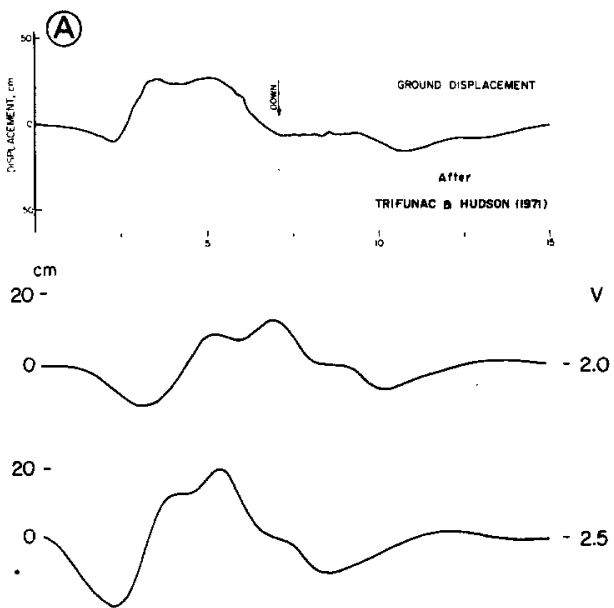

20 -

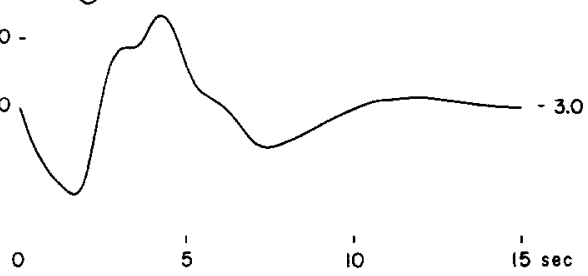

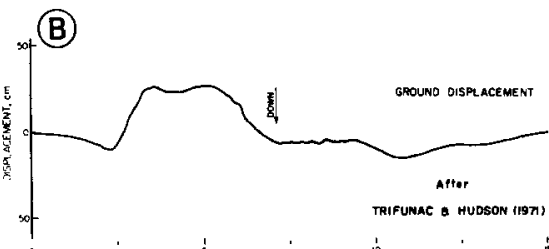
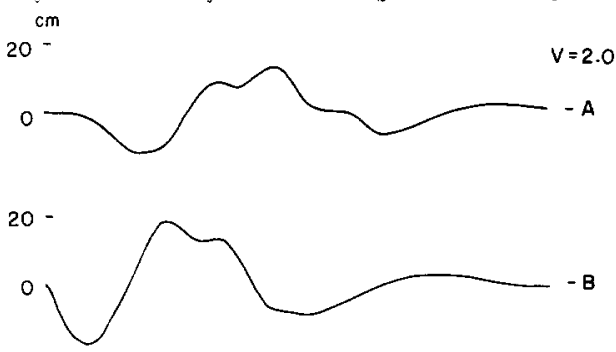

20

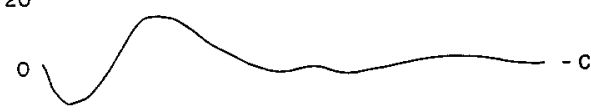

0

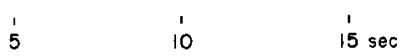

FIG. 11. Integrated vertical ground displacements at the Pacoima Dam, after Trifunac and Hudson (1971), and the computed displacements. (A) $v=2.0,2.5$, and $3.0 \mathrm{~km} / \mathrm{sec}$. (B) three modes of faulting with $v=2.5 \mathrm{~km} / \mathrm{sec}$. (Reproduction of the integrated displacements permitted by Drs. M. D. Trifunac and D. E. Hudson.) The same explanations apply to Figures 12 and 13.

There is fair agreement in the wave form, arrival time, and absolute amplitude between the second trace $(v=2.5 \mathrm{~km} / \mathrm{sec})$ and the integrated displacement, although, slightly lower fracture velocities could improve the agreement. It is also found that allowance can be made for rise times between about 0.6 and $1.2 \mathrm{sec}$; much shorter or longer time constants introduce larger discrepancies. The theoretical traces $A, B$ and $C$ in Figure 11 (B) correspond to the three modes of fracture propagation with $\tau=1 \mathrm{sec}$ and $v=2.0$ $\mathrm{km} / \mathrm{sec}$, suggesting that bilateral faulting does not yield a better agreement with the ground motion whereas the unilateral case remains as a possibility. The above comparison seems to suggest that the recorded vertical ground motion is consistent with the assumed faulting process, but this cannot be a conclusive evidence, since this component seems strongly subject to the effect of the free surface.

This is not the case, however, for the horizontal components. Figure 12, A and B, shows, in a similar way, the computed and integrated ground displacements along the $\mathrm{S} 16^{\circ} \mathrm{E}$ direction. Although it is noticed that radial faulting with $v=2.5 \mathrm{~km} / \mathrm{sec}$, gives a 

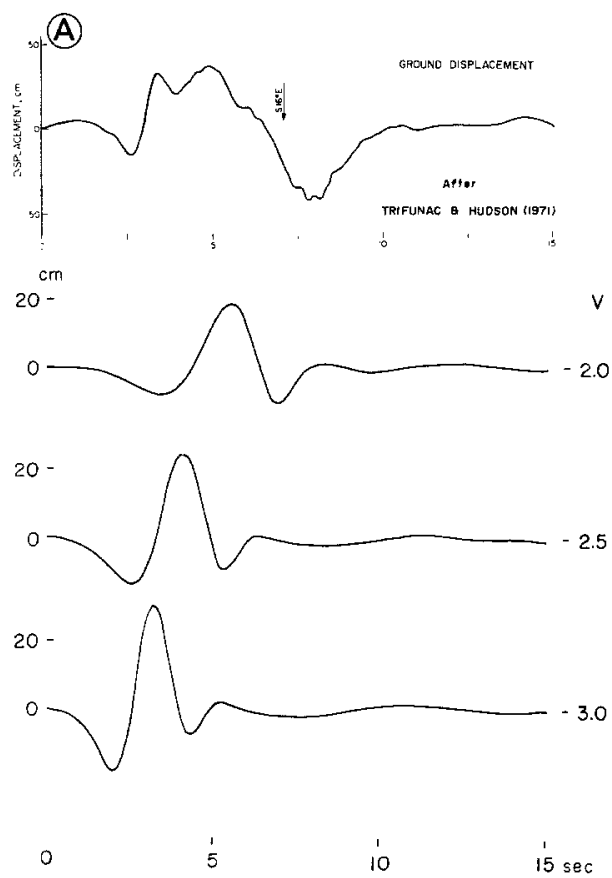
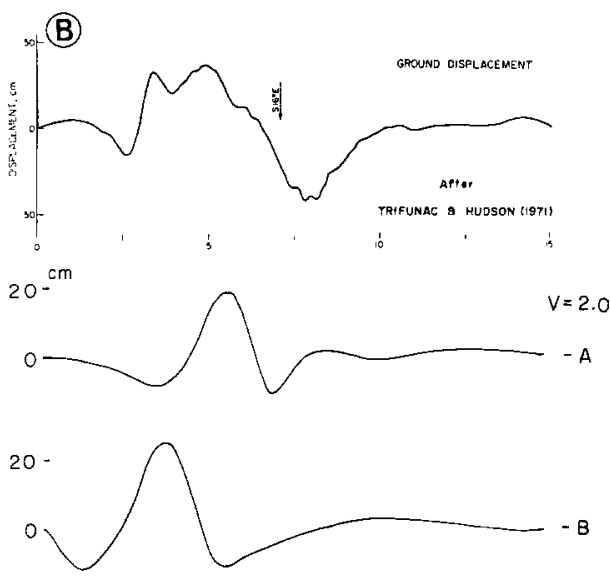

$20-$

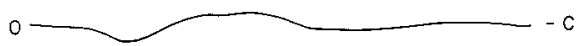

$\begin{array}{llll}0 & 1 & 1 & 1 \\ 5 & 10 & 15 \mathrm{sec}\end{array}$

Fig. 12. Integrated and computed ground displacements along the S16 $6^{\circ}$ direction. (See Figure 11 for explanation.)

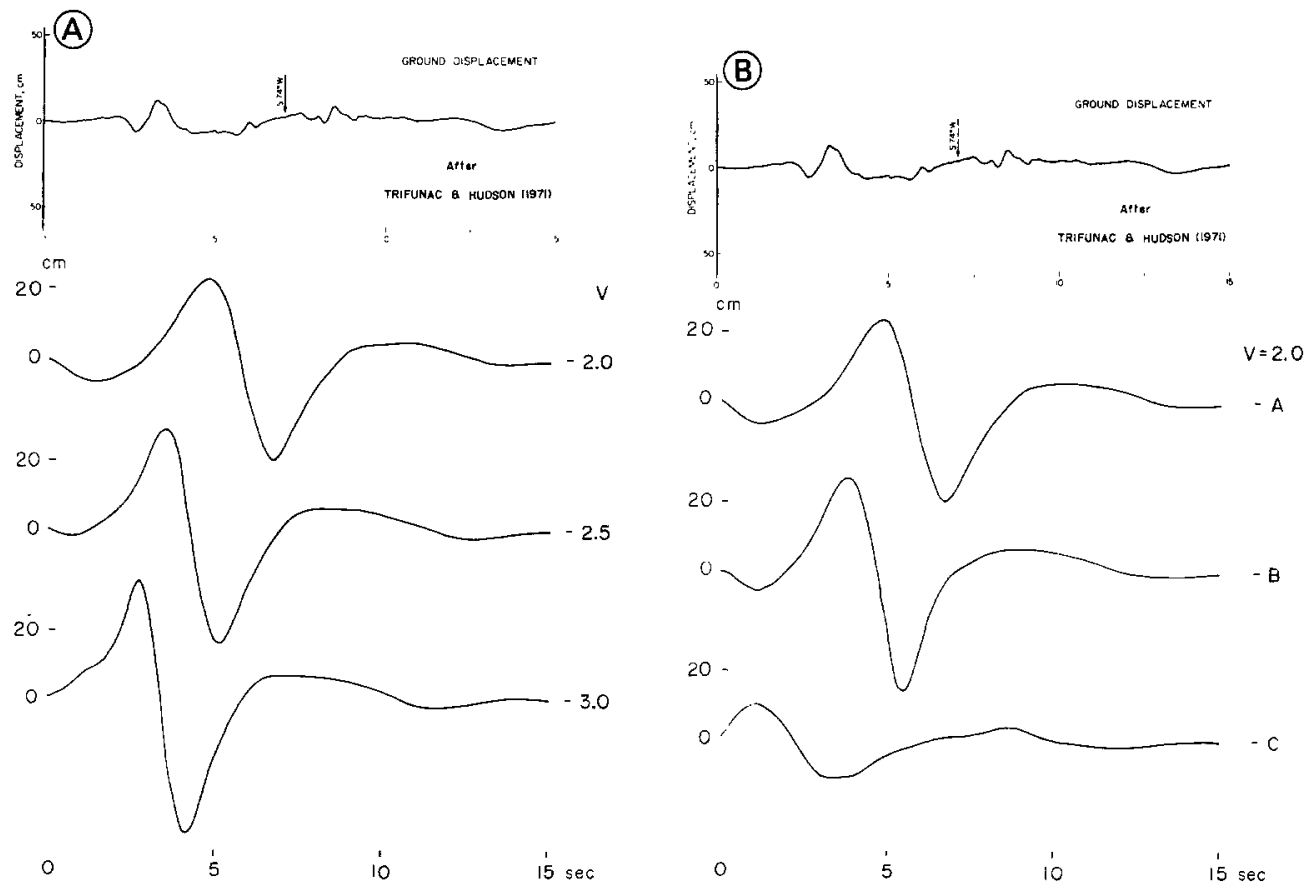

FIG. 13. Integrated and computed ground displacements along the $\mathrm{S} 74^{\circ} \mathrm{W}$ direction. (See Figure 11 for explanation.) 
fair agreement with the first $3.5 \mathrm{sec}$ of the ground displacement, a long-period motion with large amplitude beginning after $4 \mathrm{sec}$ cannot be explained by any of the theoretical traces. These later parts of the motion may be due to reflections and interferences of body waves at the ground surface or a breakout phase followed by surface waves. The corresponding displacements computed for the $S 74^{\circ} \mathrm{W}$ component are shown in Figure 13, A and B, but agreement can no longer be found with the integrated ground motion. The original (unfiltered) computed displacement (not shown here) indicates, however, some similarity to the ground motion before $4 \mathrm{sec}$, and then turns to a large step-like displacement. A plausible explanation would be that the accelerograph has failed to respond to this gentle step motion or that the arrival of a later phase has canceled the effect of the motion.

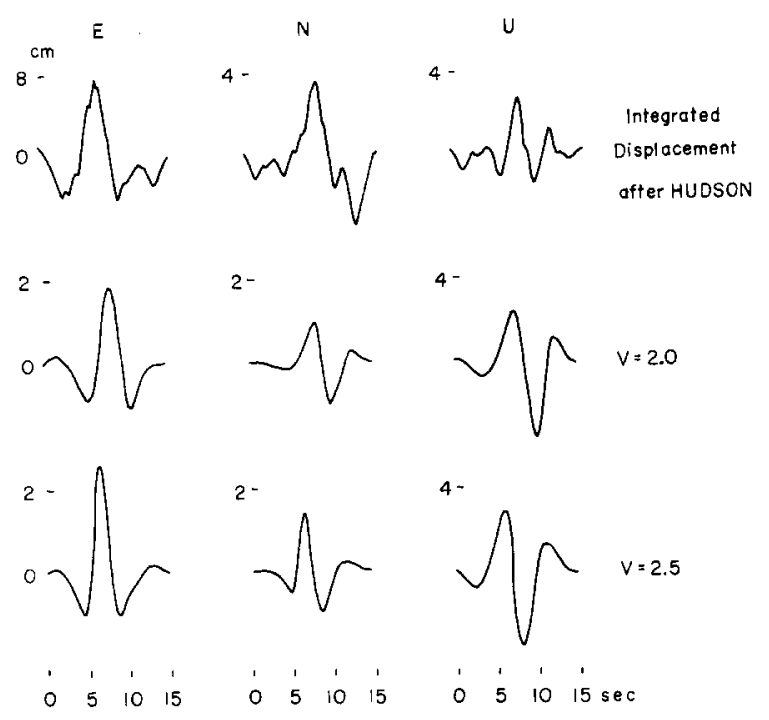

FIG. 14. Integrated ground displacements at Pasadena after Hudson (1972) and the computed displacements for $v=2.0$ and $2.5 \mathrm{~km} / \mathrm{sec}$. (Reproduction of the integrated displacements permitted by Dr. D. E. Hudson.)

We also computed dynamic displacements for the Seismological Laboratory of Caltech, Pasadena $(X=21 \mathrm{~km}, Y=-28 \mathrm{~km})$. The integrated displacements on the three components for this station (Hudson, 1972) show good consistency with those for the other three locations in Pasadena. The computed traces shown in Figure 14 are from radial faulting with the same time constant for two assumed fracture velocities. We see that the wave form of the observed ground motion may be well explained by the velocities around $2.0-2.5 \mathrm{~km} / \mathrm{sec}$, although their horizontal amplitudes are considerably larger than the theoretical prediction. It is also found that somewhat longer rise times up to about $2 \mathrm{sec}$ do not significantly alter this situation, and that unilateral or bilateral faulting does not give a satisfactory explanation of the observations.

The discrepancy may be attributed to an amplification effect by the local surface structure around this site, but the rest might have to be reconciled by introducing larger dislocations at depth. However, these are inconsistent not only with the observed tectonic movements but with the ground amplitudes at the Pacoima Dam. Another explanation is that the horizontal ground displacements might have been amplified by converted body waves and surface waves. Because we believe that these problems should be solved under more realistic environments, we did not make further attempts to reconcile the above discrepancies. 


\section{DisCUSSION}

In the present study, we made attempts to interpret static displacements, strain and tilt changes and dynamic near-field displacements from the San Fernando earthquake, in terms of the unified fault models consistent with the spatial distribution of aftershocks, focal mechanism of the main shock, and the geological features of surface fault breakage. Although the static displacements and strain changes have been investigated in a similar way by Savage et al., (1972) and Canitez and Toksöz (1972), their simplified fault models are not directly related to the aftershock area, and do not seem to give a full explanation to the pronounced uplift of the ground. We think that these problems have been improved in our model by taking a fault plane covering the area and introducing slip dislocation decreasing with depth. It also seems that some of the dynamic ground dispiacements recorded in the near-field are consistent with our model, although a firm conclusion cannot be drawn before more complete analysis is made.

It should be mentioned here that the amount of slip dislocation over the fault plane cannot be independent of stress distribution around the plane prior to the earthquake and the structure in the region concerned. The present dislocation theory does not involve pre-earthquake environments, and the structure is oversimplified by a half-space model in this study. Nevertheless, it may be reasonable to accept the present result that a rather small dislocation less than $30 \mathrm{~cm}$ initiating at the hypocenter increases toward the ground surface to 3.5 to $4 \mathrm{~m}$ during fracture propagation over the fault plane, because the strength of rocks and, hence, frictional resistance to faulting would decrease at shallower depths. For this reason, the general trend of the dislocations decreasing with depth would not be significantly changed, even if the structures near the surface and of the upper crust are taken into consideration. Actually, similar trends have been obtained by Jungels (personal communication, 1972) using the two-dimensional finite element technique which deals with a probable structure. There remains a possibility, however, that the dislocations decrease again near the surface because of low rigidity materials there (Jungels, personal communication, 1972), in view of the observed surficial displacements.

The distribution of dislocations derived here may be considered as a manifestation of the pre-earthquake stress distribution if some allowance is made for the geological structure. It is possible, on the other hand, to infer the state of stress release and concentration accompanied by the faulting directly from the dislocations. The large dislocations near the ground surface will release larger stresses, which seem to be one reason why there were almost no aftershocks just north of the surface fault traces, whereas high aftershock activity at the edge of slippage in the north and deeper zone seems to correspond to possibly low stress release or high stress concentration there, although complete calculations are needed to know more details of the stress changes around this region.

Because in our fault model, the seismic moment and stress drop of each surface element are functions of depth, we evaluate the overall quantities in the following way, $M_{0}=$ $\iint \mu \Delta u(Z) d \Sigma=1.1 \times 10^{26}$ dyne $\cdot \mathrm{cm}$ for model $\mathrm{D}$, if $\mu$ is taken to be $3 \times 10^{11} \mathrm{dyne} / \mathrm{cm}^{2}$. Inasmuch as the fault plane has a total area of $A=255 \mathrm{~km}^{2}$, the average dislocation over the plane is, $\bar{D}=M_{0} / \mu A=1.4 \mathrm{~m}$, and the stress drop is estimated to be 65 bars, using the formula of Keylis-Borok (1959), or 40 bars using that of Chinnery (1969). It is found that the seismic moment calculated here is of the same order as in the static models of Savage et al. (1972) and Canitez and Toksöz, (1972), but somewhat larger than that derived from teleseismic body- and surface-wave spectra (Wyss and Hanks, 1972; Canitez and Toksöz, 1972). The estimated stress drop seems slightly larger for shallow earthquakes with this order of magnitude, but does not exceed the effective 
TABLE 3

Fault Parameters

\begin{tabular}{lc}
\hline Dip & $52^{\circ}$ \\
Dip direction & $26^{\circ}-20^{\circ} \dagger$ \\
Strike & $\mathrm{N} 64^{\circ}-70^{\circ} \mathrm{W}$ \\
Slip direction & $244^{\circ}-233^{\circ}$ \\
Fault length (along the null vector) & $19 \mathrm{~km}$ \\
Fault width (along the slip direction) & $14 \mathrm{~km}$ \\
Fault area & $255 \mathrm{~km}$ \\
Maximum dislocation (near the surface) & $3.5-4.5 \mathrm{~m}$ \\
Dislocation (at 13 km) & $<0.3 \mathrm{~m}$ \\
Average dislocation & $1.4 \mathrm{~m}$ \\
Fracture velocity & $2.0 \sim 2.5 \mathrm{~km} / \mathrm{sec}$ \\
Seismic moment & $1.1 \times 10^{26} \mathrm{dyne} \cdot \mathrm{cm}$ \\
Stress drop & $40-65 \mathrm{bars}$ \\
\hline
\end{tabular}

\footnotetext{
* Whitcomb (1971).

† Canitez and Toksöz (1971).
}

stress of 100 bars, which has been estimated by Trifunac (1972) from the shear-wave spectra and the peak velocity of ground motion recorded during the San Fernando earthquake of February 9, 1971. The fracture velocity estimated here agrees with that derived by Bolt (1972) and Hanks (1972) from seismic ray interpretation of the Pacoima strong-motion records. All of the fault parameters in our final model $D$ are summarized in Table 3.

It should be remembered that the above dislocations, seismic moment, stress drop and the fracture velocity have been estimated under simple assumptions, and might have to be slightly modified if more complex conditions are introduced. Faulting processes including pre- and post-earthquake stress distribution may be modeled by three-dimensional finite element methods (Jungels, personal communication, 1972). Static displacement and stra in fields from slip dislocations in a multi-layered medium (Sato, 1971; Sato and Matsuura, 1972) or in a more complex structure (Jungels, personal communication, 1972) have been calculated for some models. For dynamic near-field displacements in a semi-infinite medium, complete expressions including both body and surface waves have been recently derived (Kawasaki et al., 1972). The results in the present study would provide a basis for comparing with those from the more complete analysis.

\section{ACKNOWLEDGMENTS}

The present work was made as a part of the U.S.-Japan cooperative program entitled "Joint Analysis of Seismic and Geodetic Records before and after the San Fernando Earthquake of February 9, 1971". I wish to thank Professor Clarence R. Allen and Professor Ziro Suzuki, the coordinators of the program, and the Japan Society for the Promotion of Science, who provided me the chance of visiting California. Cooperation given by the following organizations is sincerely appreciated: Seismological Laboratory, California Institute of Technology, Pasadena: National Center for, Earthquake Research, U.S. Geological Survey, Menlo Park; U.S. Earthquake Mechanism Laboratory, National Oceanic and Atmospheric Administration, San Francisco; Seismographic Station, University of California, Berkeley; Institute of Geophysics and Planetary Physics, University of California, San Diego.

I am grateful to Dr. James C. Savage, Professor Donald E. Hudson, Professor Clarence R. Allen, Dr. Mihailo M. Trifunac, and Dr. John H. Pfluke for generous permission to reproduce their data or results in advance of publication, or from their papers. Professor Bruce A. Bolt kindly read through the manuscript and provided suggestions for its improvement. Professor Hiroo Kanamori also gave some useful suggestions. I benefited from conversations on this study with Drs. Pierre Jungels, Thomas C. 
Hanks, James Whitcomb, Ralph Alewine and Tuneto Kurita at the Seismological Laboratory, Caltech, Dr. Hiroshi Sato and Mr. Akio Kuroiso, my colleagues in this program, and with Dr. Kazuo Oike and Mr. Shuzo Takemoto at our Institute. My thanks are also due Mrs. Ritsuko Koizumi and Yoko Mikumo for assistance in the present work and preparation of the manuscript.

The computations involved were made partly at the Data Processing Center, Kyoto University, and partly at the Computing Center of the California Institute of Technology.

\section{REFERENCES}

Aki, K. (1968). Seismic displacements near a fault, J. Geophys. Res. 73, 5359-5376.

Ando, M. (1971). A fault-origin model of the great Kanto earthquake of 1923 as deduced from geodetic data, Bull. Earthquake Res. Inst. Tokyo Univ. 49, 19-32.

Allen, C. R., G. R. Engen, T. C. Hanks, J. M. Nordquist, and W. R. Thatcher (1971). Main shock and larger aftershocks of the San Fernando earthquake, February 9 through March 1, 1971, U.S. Geol. Survey, Prof. Paper 733, 17-20.

Allen, C. R., T. C. Hanks, and J. H. Whitcomb (1972). San Fernando earthquake: seismological studies and their tectonic implications, Calif. Div. Mines Geol. Bull. (in press).

Berger, J. (1971). Some observations of the San Fernando, California earthquake with a laser strain meter, U.S. Geol. Survey, Prof: Paper 733, 150-152.

Bolt, B. A. (1972). San Fernando rupture mechanism and the Pacoima strong motion record, Bull. Seism. Soc. Am. 62, (in press).

Bolt, B. A. and I. Gopalakrishnan (1972). San Fernando earthquake 1971. Aftershocks, magnitude, energy and fault dynamics, Calif. Div. Mines Geol. Bull. (in press).

Burford, R. O., R. O. Castle, J. P. Church, W. T. Kinoshita, S. H. Kirby, R. T. Ruthven, and J. C Savage (1971). Preliminary measurements of tectonic movement, U.S. Geol. Survey, Prof. Paper 733, $80-85$.

Canitez, N. and M. N. Toksöz (1972). Static and dynamic study of earthquake source mechanism: San Fernando earthquake, J. Geophys. Res. 77, 2583-2594.

Chinnery, M. A. (1963). The stress changes that accompany strike-slip faulting, Bull. Seism. Soc. Am. 53, 921-932.

Chinnery, M. A. (1969). Theoretical fault models, Publ. Dominion Obs., Ottawa, 37, 211-223.

Chinnery, M. A. and J. A. Petrak (1968). The dislocation fault model with a variable discontinuity, Tectonophysics, 5, 513-529.

Dillinger, W. and A. F. Espinosa (1971). Preliminary fault-plane solution for the San Fernando earthquake, U.S. Geol. Survey, Prof. Paper 733, 142-149.

Fitch, T. J. and C. H. Scholz (1971). Mechanism of underthrusting in southwest Japan: A model of convergent plate interactions, J. Geophys. Res. 76, 7260-7292.

Hanks, T. C. (1972). The faulting mechanism of the San Fernando earthquake and identification of the initial rupture radiation, Chap. V of Ph.D. Thesis, Caltech.

Hanks, T. C., T. H. Jordan, and J. B. Minster (1971). Precise locations of aftershocks of the San Fernando earthquake 2300 (GMT) February 10-1700 February 11, 1971, U.S. Geol. Survey, Prof. Paper 733, 21-23.

Haskell, N. A. (1969). Elastic displacements in the near-field of a propagating fault, Bull. Seism. Soc. Am. 59, 865-908.

Hastie, L. M. and J. C. Savage (1970). A dislocation model for the 1964 Alaska earthquake, Bull. Seism. Soc. Am. 60, 1389-1392.

Hudson, D. E. (1971). Strong-motion instrumental data on the San Fernando earthquake of February 9 , 1971, A Report of Earthquake Eng. Res. Lab., Caltech, and Seism. Field Survey, NOOA.

Hudson, D. E. (1972). Local distribution of strong earthquake ground motions, Bull. Seism. Soc. Am.62, (in press).

Japanese Network of Crustal Movement Observatories (1970). Spatial distribution of strain-steps associated with the earthquake of the central part of Gifu Prefecture, September 9, 1969, Bull. Earthquake Res. Inst. Tokyo Univ. 48, 1217-1233.

Jungels, P. and D. L. Anderson (1971). Strains and tilts associated with the San Fernando earthquake, U.S. Geol. Survey, Prof. Paper 733, 77-79.

Kamb, B., L. T. Silver, M. J. Abrams, B. A. Carter, T. H. Jordan, and J. B. Minster (1971). Pattern of faulting and nature of fault movement in the San Fernando earthquake, U.S. Geol. Survey, Prof. Paper 733, 41-54. 
Kanamori, H. (1971). Seismological evidence for a lithospheric normal faulting - the Sanriku earthquake of 1933, Phys. Earth Planet. Interiors 4, 289-300.

Kanamori, H. (1972). Determination of effective tectonic stress associated with earthquake faultingTottori earthquake of 1943 (in press):

Kawasaki, I., Y. Suzuki and R. Sato (1972). Seismic waves due to a double couple source in a semiinfinite medium, paper read at the annual meeting of the Seismological Society of Japan, 1971.

Keylis-Borok, V.I. (1959). On estimation of the displacement in an earthquake source and of source dimension, Ann. Geofis. 12, 205-214.

Maley, R. P. and W. K. Cloud (1971). Preliminary strong-motion results from the San Fernando earthquake of February 9, 1971, U.S. Geol. Survey, Prof. Paper 733, 163-176.

Mansinha, L. and D. E. Smylie (1971). The displacement fields of inclined faults, Bull. Seism. Soc. Am. 61, 1433-1440.

Maruyama, T. (1963). On the force equivalents of dynamical elastic dislocations with reference to the earthquake mechanism, Bull. Earthquake Res. Inst., Tokyo Univ. 41, 467-486.

Maruyama, T. (1964). Statical elastic dislocations in an infinite and semi-infinite medium, Bull. Eartkquake Res. Inst., Tokyo Univ. 42, 289-368.

Plafker, G. and J. C. Savage (1970). Mechanism of the Chilean earthquakes of May 21 and 22, 1960, Bull. Geol. Soc. Am. 81, 1001-1030.

Press, F. (1965). Displacements, strains and tilts at teleseismic distances, J. Geophys. Res. 70, $2395-2412$.

Sato R. (1971). Crustal deformation due to dislocation in a multi-layered medium, J. Phys. Earth 19, 31-46.

Sato, R. and M. Matsuura (1972). Static strains on the ground surface due to a fault in a multi-layered medium, paper read at the annual meeting of the Seism. Soc. Japan, 1972.

Savage, J. C. and L. M. Hastie (1966). Surface deformation associated with dip-slip faulting, J. Geophys. Res. 71, 4897-4904.

Savage, J. C. and L. M. Hastie (1969). A dislocation model for the Fairview peak, Nevada earthquake, Bull. Seism. Soc. Am.59, 1937-1948.

Savage, J. C., R. O. Burford and W. T. Kinoshita (1972). Earth movements from geodetic measurements, (in press).

Steketee, J. A. (1958). Some geophysical application of the elasticity theory of dislocations, Can. J. Phys. 36, 1168-1198.

Trifunac, M. D. (1972). Stress estimates for the San Fernando, California, earthquake of February 9, 1971: Main event and thirteen aftershocks, Bull. Seism. Soc. Am. 62,721-750.

Trifunac, M. D. and D. E. Hudson (1971). Analysis of the Pacoima Dam accelerogram-San Fernando, California, earthquake of 1971, Bull. Seism. Soc. Am. 61, 1393-1141.

U.S. Geological Survey Staff (1971). Surface faulting, U.S. Geol. Survey, Prof. Paper 733, 55-76.

Wesson, R. L. and J. F. Gibbs (1971). Crustal structure in the vicinity of the San Fernando, California earthquake of 9 February 1971, EOS.52, 864.

Wesson, R. L., W. H. K. Lee, and J. F. Gibbs (1971). Aftershocks of the earthquake, U.S. Geol. Survey, Prof. Paper 733, 24-29.

Whitcomb, J. H. (1971). Fault-plane solutions of the February 9, 1971, San Fernando earthquake and some aftershocks, U.S. Geol. Survey, Prof. Paper 733, 30-32.

Whitten, C. A. (1971). Crustal-movement surveys and pre-earthquake strain analysis, U.S. Geol. Survey, Prof. Paper 733, 161-162.

Wyss, M. and T. C. Hanks (1972). The source parameters of the San Fernando earthquake inferred from teleseismic body waves, Bull. Seism. Soc. Am. 62, 591-602.

\section{Disaster Prevention Research Institute,}

KYOTO UNIVERSITY,

UJI, KYOTO, JAPAN

Manuscript received August 1, 1972. 